EESTI NSV TEADUSTE AKADEEMIA TOIMETISED. GEOLOOGIA

ИЗВЕСТИЯ АҚАДЕМИИ НАУК ЭСТОНСКОИ ССР. ГЕОЛОГИЯ

PROCEEDINGS OF THE ACADEMY OF SCIENCES OF THE ESTONIAN SSR. GEOLOGY

$1985,34,4$

П. ИЫГАР

удК $556.314+556.388(474.2)$

\title{
ИССЛЕДОВАНИЕ ВЛИЯНИЯ ПРИРОДНЫХ И ТЕХНОГЕННЫХ ФАКТОРОВ НА СОСТАВ ПОДЗЕМНЫХ ВОД СЕВЕРНОЙ ЭСТОНИИ
}

Әстонская ССР является регионом с развитой промышленностью и сельским хозяйством, пресные подземные воды которого широко используются для водоснабжения. Их изучение в условиях прогрессирующего действия антропогенных факторов - важная составная часть гидрогеологических исследований.

Гидрогеохимическая информация о составе подземных вод, неизбежно накапливающаяся со временем в ходе работы различных практических учреждений или в процессе исследования, естественно, неравноценна как по количеству определяемых компонентов, так и по качеству проводимых анализов. В общем количестве информации значительно преобладают результаты анализов «массового» вида, характеризующие содержание в подземной воде пяти-шести главных компонентов.

Обработка гидрогеохимической информации такого рода математическими методами - одна из возможностей выявления скрытых тенденций и изменений состава подземных вод во времени и, что особенно важно, - в региональном плане. Примером аналогичного подхода может служить монографическое исследование В. В. Микалаускаса (1976), где усреднены все результаты гидрогеохимических анализов грунтовых вод Литовской ССР, полученные при проведении комплексной гидрогеологической съемки среднего масштаба. Усреднением большого количества гидрохимических данных как средством вычисления гидрохимического фона пользуются также и за рубежом. Так, к началу 70-х годов вычислены средние значения концентрации ионов $\mathrm{Fe}$ “; $\mathrm{Cl}^{\prime}$ и $\mathrm{SO}_{4}$ ", величин общей жесткости, общей минерализации и $\mathrm{pH}$ по данным огромного количества эксплуатационных скважин северо-восточных штатов США (Ground Water Contamination..., 1974).

В настоящей работе в качестве исходных данных использованы результаты химических анализов воды (анионы: $\mathrm{HCO}_{3}$ ", $\mathrm{SO}_{4}$ " и $\mathrm{Cl}$ ', катионы $\mathrm{Ca}$ ", $\mathrm{Mg}^{\prime}$ и $\mathrm{Na}^{*}+\mathrm{K}^{*}$ ), полученные в ордовикских и силурийских карбонатных породах Северной Эстонии при бурении эксплуатационных скважин в 1958-1974 гг. Многие из них заложены при строительстве новых ферм, поэтому результаты анализов воды характеризуют относительно незагрязненное состояние подземных вод в данный момент времени. К достоинствам эксплуатационных скважин можно отнести и сравнительно узкий интервал вскрытия коренных пород (начиная от 15 до 25 м от поверхности земли).

Эти данные, относящиеся к рассматриваемым годам, являются основной информацией о гидрохимическом составе подземных вод. Результаты статистической обработки данных можно рассматривать как начальные точки мониторинга, цель которого - наблюдение за общим состоянием подземных вод. По мере накопления новых данных (с привлечением данных гидрогеологического картирования 70-х годов) 
аналогичным способом можно исследовать и общее состояние вод за последующие периоды.

В качестве расчетных значений в настоящей работе определены не средние арифметические или медианные значения химического компонента, а условные математические ожидания. По величинам водопроводимостей $T_{i r}$ они являются средневзвешенным химическим составом $c_{i k}$ выбранного интервала залегания подземных вод (Йар, 1974)

$$
c_{i k}=\sum_{r=1}^{R} \frac{p_{i r}}{\sum_{i=1}^{N} p_{i r}} \cdot c_{r k}=\sum_{r=1}^{R} P_{i r} \cdot c_{r k},
$$

где $p_{i r}=T_{i r} / \sum_{i=1}^{N} T_{i r}, c_{i k}-$ средневзвешенная концентрация $k$-го иона $i$-го водоносного горизонта (интервала), $P_{i r}-$ условная вероятность принадлежности величины $c_{r k}$ к составу $c_{i k}, c_{r k}-$ концентрация $k$-го иона в воде, извлекаемой из $r$-ой скважины $(r=1,2, \ldots, R ; R-$ число скважин в анализируемой группе), $T_{i r}$ - водопроводимость $i$-го водоносного горизонта в скважине $r$.

На основе большого количества начальных данных (при бурении скважин), предварительно сгруппированных по времени и по территориальному принципу, определены средневзвешенные концентрации шести главных компонентов подземной воды. Основная цель работы определить общую направленность гидрогеохимических изменений в подземных водах верхней части карбонатной толщи Северной Әстонии за рассматриваемые годы, а тем самым и влияние хозяйственной деятельности человека. Одновременно данный анализ дает возможность оценить и элиминировать из комплексного анализа влияние некоторых природных факторов, так как повышенное содержание некоторых главных компонентов может оказаться не только результатом антропогенных (техногенных) факторов, но и следствием природных процессов (Микалаускас, 1981).

К одним из таких природных явлений относятся как вертикальная, так и горизонтальная гидрогеохимические зональности - хорошо известная закономерность гидрогеохимии артезианских бассейнов. На территории Эстонской ССР эта закономерность проявляется в изменении химического состава подземных вод (от гидрокарбонатных магниево-кальциевых до гидрокарбонатно-хлоридных кальциево-натриевых) и в увеличении общей минерализации с глубиной (Верте, 1965). Один из первых признаков зональности - смена магниевокальциевых вод кальциево-магниевыми. В прибрежных районах Западной Эстонии горизонтальная гидрогеохимическая зональность выражена тем, что в верхних водоносных горизонтах по мере приближения к берегу моря гидрокарбонатные воды становятся хлоридно-гидрокарбонатными, а затем сменяются солоноватыми хлоридными водами, общая минерализация которых увеличивается (Верте, 1965; Пилль, 1974).

В табл. 1 указаны приблизительные глубины появления признаков вертикальной гидрогеохимической зональности, определенные по величинам процент-эквивалентов шести главнейших катионов и анионов. В ней отражены результаты вычислений средневзвешенных концентраций главных компонентов по (1), выполненные на основе данных почти о 800 эксплуатационных скважинах (1958-1973), предварительно разделенных на 74 группы.

Каุк видно по табл. 1, в верхней части ордовикско-силурийского водоносного комплекса до глубины 80 м от поверхности земли распространены гидроқарбонатные магниево-кальциевые воды, которые 
Изменение с глубиной гидрохимического типа подземных вод силурийско-ордовикского водоносного комплекса Северной Эстонии

\begin{tabular}{c|c|c|c|c|c}
\hline \multirow{2}{*}{$\begin{array}{l}\text { Местоположение } \\
\text { группы скважин }\end{array}$} & \multicolumn{4}{|c}{ Глубина залегания подземных вод от поверхности земли, м } \\
\cline { 2 - 6 } & $20-30$ & $40-50$ & $60-70$ & $80-90$ & $100-120$ \\
\hline 1 & 2 & 3 & 4 & 5 & 6 \\
\hline
\end{tabular}

I. Северо-Западная Эстония (севернее водораздела)

Падизе

Рийзипере

Кнйза

Раазику

Хагери

Кохнла

Перила

Варди

Пурила, Ярлепа, Рапла

Юуру, Куйметса Козе

Алавере

Арду, Аравете, Амбла

II. Северо-Западная Эстония (южнее водораздела)

Райккюла, Куузику Локута

Уускюла, Кехтна,

Кядва, Кяру

Ярваканди

Kepry

Вяндра

Лаупа

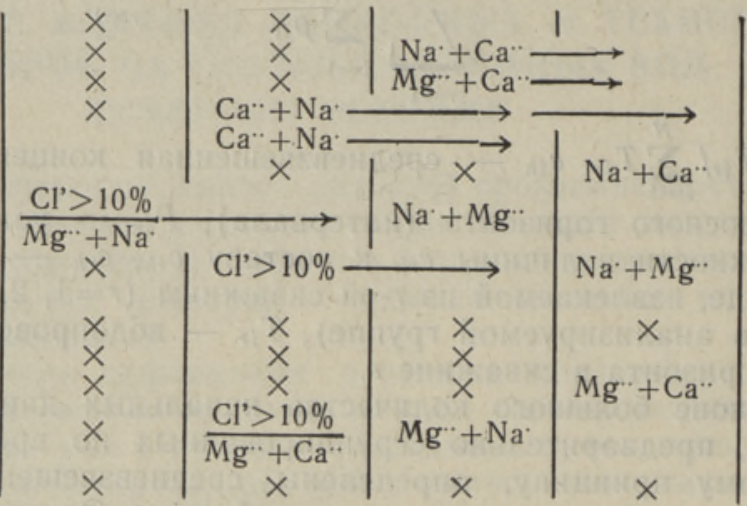

$\mid$

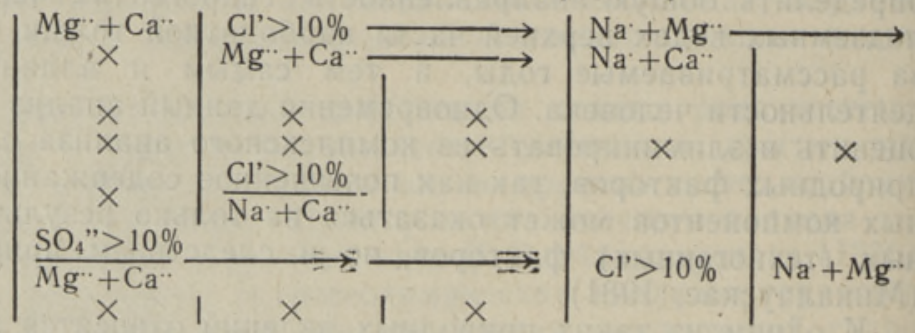

III. Северный склон Пандивереской возвышенности

Янеда, Лехтсе, Тапа

Вийтна, Вохнья, Хальяла

Кадрина

Удрнку

Рягавере

Ваэкюла, Виру-Яагупи, Кюти, Лазила,

Поркуни, Вяйке-

Маарья, Тамсалу,

Виру-Роэла
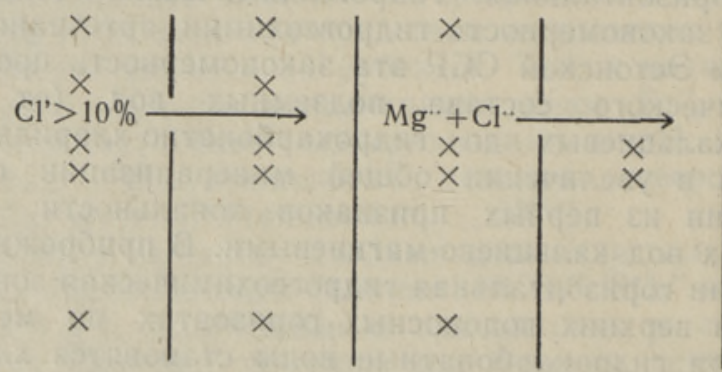

IV. Южный склон Пандивереской возвышенности и Вооремаа

Сейдла

Ваянгу

Роосна-Аллику

Ярва-Яани

Варангу, Кнльтси

Симуна

Паасвере

Анна

Водья

Пеэтри

Коэру, Ракке

Мюйслери

Пайде
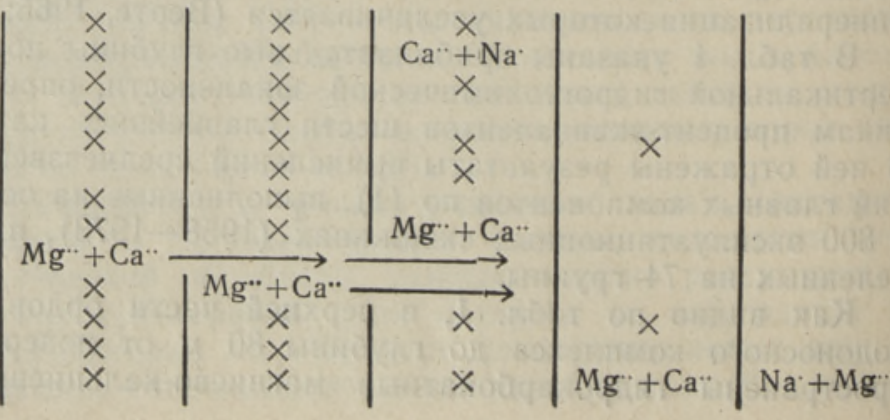


\begin{tabular}{|c|c|c|c|c|c|}
\hline 1 & 2 & 3 & 4 & 5 & 6 \\
\hline Тюри & $x$ & $x$ & $\mathrm{Cl}^{\prime}>10 \%$ & $\mathrm{Na}+\mathrm{Mg}$ & \\
\hline Имавере & $x$ & $x$ & $\mathrm{Ca}+{ }^{*}+\mathrm{Na}^{+}$ & $\frac{\mathrm{Cl}^{\prime}>10 \%}{\mathrm{Na}+\mathrm{M} \sigma}$ & \\
\hline $\begin{array}{l}\text { Выхма, Пылтсамаа } \\
\text { Адавере } \\
\text { Пыгева } \\
\text { Вооре, Торма }\end{array}$ & $\begin{array}{l}x \\
x \\
x \\
x\end{array}$ & $\begin{array}{l}x \\
x \\
x \\
x\end{array}$ & $\begin{array}{c}\times \\
\mathrm{Na}+\mathrm{Mg} \\
\times \\
\times\end{array}$ & $\begin{array}{c}\times \\
\times \\
\mathrm{Mg}+\mathrm{Ca}\end{array}$ & $\begin{array}{c}\mathrm{Ca}^{*}+\mathrm{Na} \cdot \\
\mathrm{Na}+\mathrm{Ca}^{*} \\
\times\end{array}$ \\
\hline Паламузе & $x$ & $x$ & $\frac{\mathrm{Cl}^{\prime}>10 \%}{\mathrm{Mg}{ }^{*}+\mathrm{Ca}^{*}}$ & $\Longrightarrow$ & $\mathrm{Na}+\mathrm{Ca}^{*}$ \\
\hline Умбузи & $\frac{\mathrm{Cl}^{\prime}>10 \%}{\mathrm{Na}+\mathrm{Ca}^{\prime}}$ & & & & \\
\hline $\begin{array}{l}\text { Пуурмани } \\
\text { Ярве }\end{array}$ & $\begin{array}{l}\times \\
\times\end{array}$ & $\begin{array}{l}x \\
\times\end{array}$ & $\begin{array}{l}x \\
x\end{array}$ & $x$ & \\
\hline
\end{tabular}

Примеч ание. Знаком «Х» отмечен типовой гидрохимический состав (анионы: $\mathrm{HCO}_{3}^{\prime} \mid>80, \mathrm{Cl}^{\prime}$ и $\mathrm{SO}_{4}^{\prime \prime} \mid<10$ процент-эквивалентов; катионы: $\left.\mathrm{Ca}^{*}>\mathrm{Mg} \cdot>\mathrm{Na}+\mathrm{K} \cdot\right)$.

на глубине свыше 100 м превращаются в гидрокарбонатные кальциевомагниевые и магниево-натриевые. Первоначальный гидрохимический тип сохранился лишь на своде Пандивереской возвышенности. В Западной Эстонии ближе к побережью глубина соответствующего типа воды уменьшается (Вяндра, Кергу, Куузику).

Таб̆лица 2

Концентрации основных катионов и анионов подземных вод

в зонах распространения тектонических нарушений, погребенных долин и эрозионных врезов

\begin{tabular}{|c|c|c|c|c|c|c|c|c|c|c|}
\hline \multirow{3}{*}{ 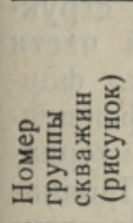 } & \multirow{3}{*}{ 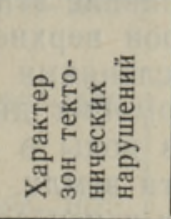 } & \multirow{3}{*}{ 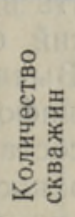 } & \multicolumn{5}{|c|}{$\begin{array}{c}\text { Средневзвешенная концентра- } \\
\text { ция (мг/л) на глубине } \\
15-30 \text { м }\end{array}$} & \multirow{2}{*}{\multicolumn{3}{|c|}{ 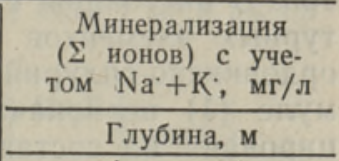 }} \\
\hline & & & \multirow[b]{2}{*}{$\mathrm{HCO}_{3}^{\prime}$} & \multirow[b]{2}{*}{$\mathrm{SO}_{4}^{\prime \prime}$} & \multirow[b]{2}{*}{$\mathrm{Cl}^{\prime}$} & \multirow[b]{2}{*}{$\mathrm{Ca}^{*}$} & \multirow[b]{2}{*}{$\mathrm{Mg}$} & & & \\
\hline & & & & & & & & $15-30$ & $30-45$ & $45-60$ \\
\hline 2 и 5 & редкие зоны & 9 & 285,0 & 21,0 & 14,2 & 55,6 & 24,9 & 417,8 & 466,1 & 469,0 \\
\hline 1 и 7 & сй & 9 & 277,8 & 36,7 & 30,3 & 53,1 & 21,0 & 464,0 & & 528,1 \\
\hline & $\begin{array}{c}\text { сплошные } \\
\text { зоны }\end{array}$ & 8 & 396,5 & 29,3 & 34,8 & 51,8 & & 613,8 & & 561,8 \\
\hline 11 & $\mid \begin{array}{l}\text { погребенные } \\
\text { долины и } \\
\text { редкие } \\
\text { зоны }\end{array}$ & 7 & 300,3 & 15,5 & 14,4 & 56,1 & 26,9 & - & 429,4 & 440,8 \\
\hline 12 & $\begin{array}{c}\text { погребенные } \\
\text { долины и } \\
\text { предпола- } \\
\text { гаемые } \\
\text { зоны }\end{array}$ & 12 & 346,1 & 22,2 & 11,1 & 68,6 & 29,8 & 492,2 & 494,3 & 495,3 \\
\hline 13 и 16 & $\begin{array}{l}\text { погребенные } \\
\text { долины }\end{array}$ & 9 & 332,9 & 26,2 & 12,5 & 58,5 & 26,3 & - & 488,5 & 477,8 \\
\hline 13 и 16 & $\begin{array}{c}\text { Азериская } \\
\text { зона }\end{array}$ & 10 & 278,3 & 23,2 & 14,1 & 58,7 & 20,2 & 415,9 & 433,5 & 418,4 \\
\hline 17 и 20 & $\begin{array}{l}\text { редкие зоны } \\
\text { сплошные }\end{array}$ & 9 & $\begin{array}{l}328,3 \\
355\end{array}$ & 18,4 & 11,2 & 67,7 & 26,1 & $\overline{5}$ & & \\
\hline & $\begin{array}{c}\text { сплошные } \\
\text { зоны }\end{array}$ & & 355,7 & & 9,1 & & & 515,4 & & \\
\hline 15 & $\begin{array}{c}\text { Азериская } \\
\text { зона }\end{array}$ & 7 & 316,5 & 22,2 & 11,2 & 69,6 & 27,3 & 453,1 & 457,6 & 417,1 \\
\hline 20 & $\begin{array}{c}\text { Ахтмеская } \\
\text { зона }\end{array}$ & 9 & 344,0 & 22,3 & 14,4 & 74,4 & 25,9 & - & 497,7 & 457,9 \\
\hline 19 & $\begin{array}{c}\text { сплошные } \\
\text { зоны }\end{array}$ & 8 & 311,3 & 15,6 & 15,7 & 70,7 & 23,1 & 447,4 & 462,6 & 431,5 \\
\hline 18 & $"$ & 9 & 385,4 & 25,0 & 15,8 & 87,2 & 30,0 & 550,1 & 566,1 & 564,6 \\
\hline
\end{tabular}




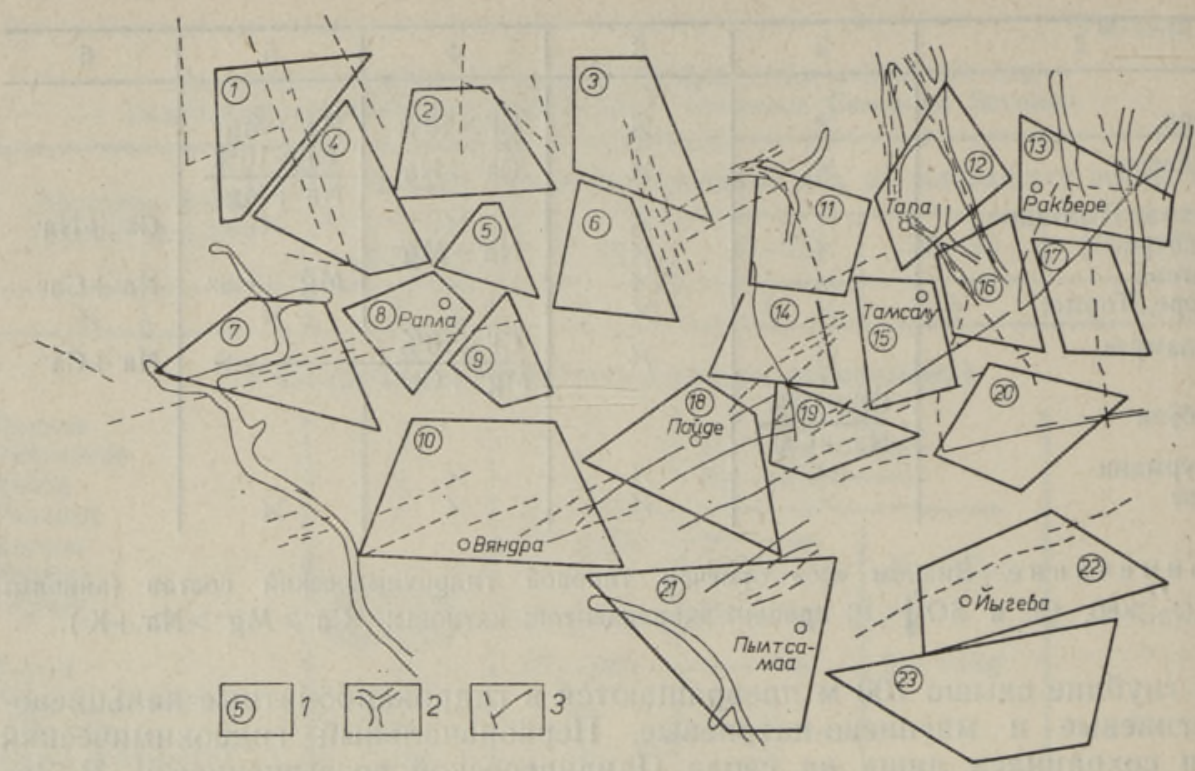

Расположение расчетных площадей. 1 - номер расчетной площади, 2 - погребенные долины и эрозионные врезы, 3 - зоны тектонических нарушений (по данным мелкомасштабного геологического картирования Управления геологии ЭССР).

Зоны тектонических нарушений и погребенных долин в Северной Эстонии принято рассматривать как каналы, питающие нижние водоносные горизонты атмосферными осадками и водами верхних горизонтов. В настоящей статье сделана попытка указать влияние этих структурных элементов на общий гидрогеохимический фон верхней части ордовикско-силурийской карбонатной толщи. Вычислениями по формуле (1) первоначальная гидрогеохимическая информация дифференцирована на составляющие, характеризующие состав воды в интервалах глубин $15-30,30-45$ и $45-60$ м от поверхности земли. Проанализированы данные о 114 скважинах, расположенных в непосредственной близости (меньше 1 км) от исследуемых зон *. Скважины глубиной не больше 70 м были разделены на 13 групп, по 7-12 скважин в каждой (табл. 2). Для дифференцирования веса разных скважин в зависимости от степени близости зон тектонических нарушений и от характера последних (густоты зон, флексурообразности в плане) подобраны коэффициенты в пределах $0,4-1,0$, на которые были умножены величины условных вероятностей.

Особое внимание было уделено изучению гидрогеологической роли мощных зон Кундаского, Азериского и Ахтмеского тектонических нарушений, а также погребенных долин на северном склоне Пандивереской возвышенности (рисунок), для прослеживания которых составлены и проанализированы отдельные группы скважин. При сопоставлении результатов вычислений в пределах этих групп с соответствующими данными о группах скважин вне зон обращает на себя внимание меньшая изменчивость суммы ионов (косвенно характеризующая и общую минерализацию) с глубиной для скважин в пределах зон, чем для скважин вне зон, что свидетельствует об интенсивном водообмене между водоносными слоями разных глубин. Если в зонах юго-западного склона Пандивереской возвышенности преобладают высокоминерализованные воды (из глубин ордовикско-силурийского комплекса), то в сводовой и

* В качестве исходного материала использованы результаты мелко- и крупномасштабного геологического картирования, проведенные Управлением геологии ЭССР. 


\begin{tabular}{c|c|c|c|c|c|c|c|c|c|c}
\hline 1 & 2 & 3 & 4 & 5 & 6 & 7 & 8 & 9 & 10 & 11 \\
\hline \multirow{4}{*}{$1967-1969$} & & 354,0 & 22,1 & 16,5 & 70,5 & 26,9 & 515,0 & & \\
& $\#$ & & 346,4 & 22,7 & 17,7 & 58,3 & 30,7 & & 506,4 & \\
& $\#$ & & 331,1 & 25,3 & 18,9 & 47,8 & 33,0 & & & 491,0 \\
& $1969-1973$ & & 371,7 & 21,1 & 18,7 & 71,9 & 31,4 & 537,1 & & \\
& $\#$ & & 374,8 & 23,4 & 19,8 & 68,1 & 33,6 & & 545,6 & \\
& $\#$ & & 313,8 & 19,4 & 22,4 & 46,0 & 31,6 & & & 465,6
\end{tabular}

III. Северный склон Пандивереской возвышенности

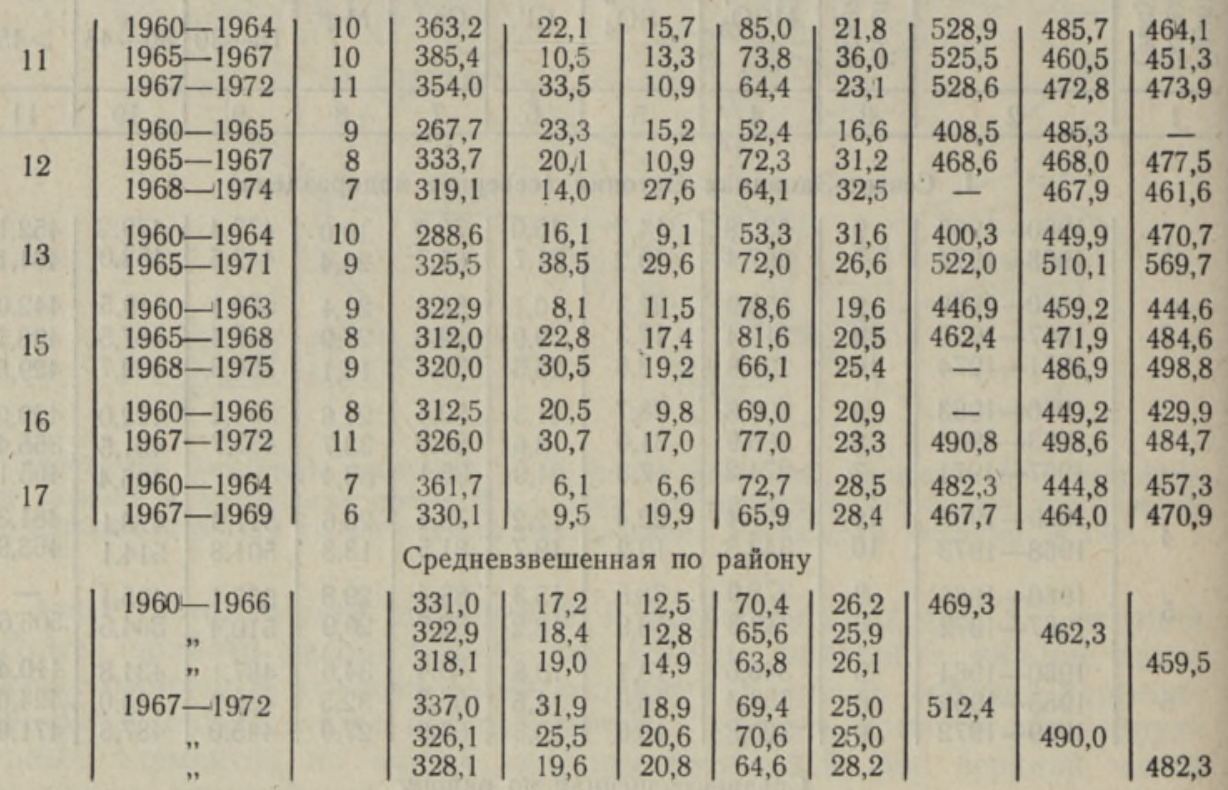

IV. Южный склон Пандивереской возвышенности и Вооремаа

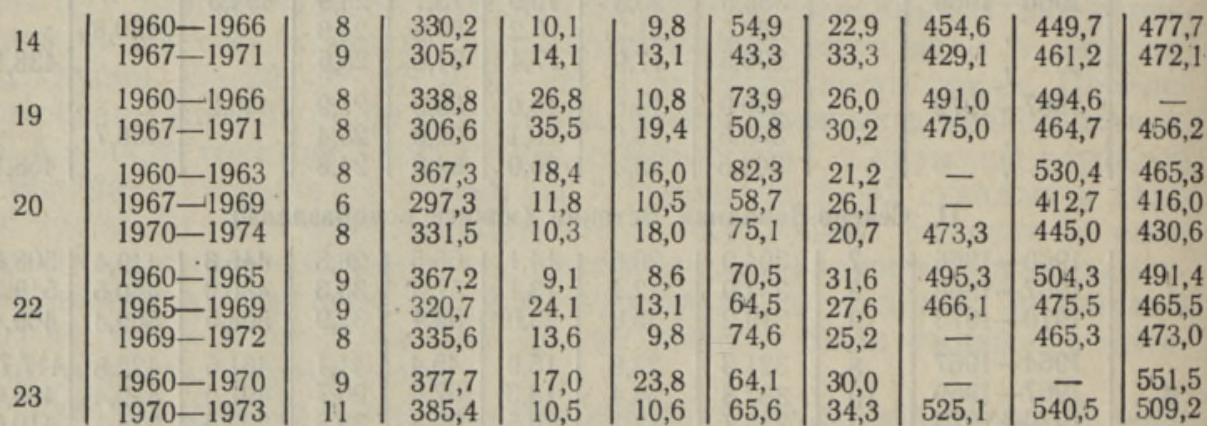
Средневзвешенная по району

\begin{tabular}{|c|c|r|r|r|r|r|r|r|r}
$1960-1966$ & 347,9 & 17,7 & 9,8 & 69,7 & 28,4 & 487,0 & & \\
$\prime \prime$ & 352,9 & 15,1 & 10,3 & 58,5 & 26,5 & & 480,7 & \\
$1967-1972$ & 354,3 & 14,0 & 15,0 & 67,9 & 26,0 & & & 502,3 \\
$"$, & 335,1 & 17,6 & 14,2 & 63,5 & 28,5 & 477,9 & & \\
$"$ & 336,9 & 16,9 & 14,6 & 64,1 & 29,4 & & 478,2 & \\
& 334,7 & 16,3 & 11,8 & 62,6 & 29,0 & & &
\end{tabular}

восточной частях возвышенности картина обратная. Там подземные воды как бы «деминерализуются», что можно объяснить хорошими условиями водообмена в пределах зон в сочетании с нисходящей фильтрацией. Аналогичная картина наблюдается также в пределах зон северозападной части исследуемой территории.

Погребенные долины и эрозионные врезы на северном склоне возвышенности, по-видимому, на состав подземных вод влияния не ока- 
зывают. Исключение составляют лишь погребенные долины вдоль рек Валгейыги и Лообу, расположенные, по данным геологического картирования, на линиях тектонических нарушений. В этом районе отмечается относительно высокая минерализация подземных вод.

В табл. 3 приведены средневзвешенные концентрации отдельных ионов по формуле (1), рассчитанные на основе данных о 508 скважинах, разделенных на 23 группы (рисунок). Сумма концентраций главных компонентов также косвенно отражает изменения общей минерализации подземных вод с глубиной и во времени. Определения характеризуют интервалы глубин залегания подземных вод в $15-30,30-45$ и 45-70 м от поверхности земли. В расчетах использованы данные о скважинах исключительно сельской местности вне зон тектонических нарушений и погребенных долин, вскрывающих водовмещающие породы на глубине не более $70 \mathrm{~m}$.

По мнению многих авторов (Гнусин, 1970; Микалаускас, 1976), увеличение общей минерализации - один из основных признаков загрязнения подземных вод. Изменения состава подземных вод большей части исследуемой территории (особенно в Раквереском и Пайдеском районах и в южной части Раплаского района) склонялись в сторону увеличения минерализации. На этой обширной территории увеличение минерализации с течением времени установлено на $90-95 \%$-ном уровне значимости (исходя из суммы ионов).

На юго-западном склоне Пандивереской возвышенности, где распространены мощные зоны тектонических нарушений, а также в Вооремаа (район мощного четвертичного покрова), уровень минерализации подземных вод за рассматриваемые годы не изменился.

Из факторов, воздействующих на природный фон подземных вод, следует прежде всего учитывать применение различных минеральных удобрений, способных повлиять на повышение концентрации любого из перечисленных выше главных компонентов (Кондратас, Микалаускас, 1973; Maastik, 1978). Просачиванию удобрений и ядохимикатов в грунтовые и подземные воды способствуют также мелиоративные работы (Kink, 1978). Из данных по территории Литовской ССР (Кондратас, 1977) следует, что количество удобрений, вносимых на 1 га, с 1961 по 1974 г. в среднем возросло, по меньшей мере, в 2 раза. Аналогичный рост количества удобрений действителен также и для территории Эстонской ССР.

Установлено, что в некоторых районах, а именно - в Харьюском и частично в Рапласком за 1966-1972 гг. минерализация подземных вод стала меньше, чем в предыдущий период (на $95 \%$-ном уровне значимости). Это касается интервала глубин 15-30 м, на бо́льшей глубине изменений в минерализации не наблюдается. Очевидно, причины такого явления следует искать в анализе агротехнических мероприятий тех лет.

Приведенная в данной статье статистическая обработка гидрогеохимической информации, выявление скрытых тенденций и закономерностей позволяют судить об изменениях в составе подземных вод и о влиянии на него различных факторов. Результаты работы косвенно характеризуют первоначальный природный фон подземных вод в региональном плане, а в дальнейшем могут быть сопоставлены с количественными показателями антропогенных и техногенных факторов в целях комплексного анализа.

\section{Л И ТЕ Р А Т У РА}

Bepтe A. Основные черты гидрогеологического строения и формирования подземных вод Эстонского артезнанского бассейна. - Изв. АН ЭССР. Сер. биол., 1965, $14,563-586$. 
Гнусин Н. П. Угроза минерализации поверхностных и грунтовых вод. - В кн.: Охрана подземных вод Украинской ССР от загрязнения и истощения. Вып. 2. Материалы I республиканского научно-технического совещания. Киев, 1970, $22-23$.

Иыгар П. Химический состав подземных вод как индикатор водоупорных свойств карбонатных пород. - Изв. АН ЭССР. Хим. Геол., 1974, 23, 161-166.

Кондратас A. P., Микалаускас В. В. Пример регионального загрязнения грунтовых вод. - В кн.: Гидрогеология СССР. Вып. 4. Влияние производственной деятельности человека на гидрогеологические и инженерно-геологические условия. М., 1973, 234-238.

Кондратас $A$. $\ddot{P}$. Интенсификация химизации сельского хозяйства как основа ее воздействия на подземные воды. - В кн.: Охрана подземных вод Прибалтики, Тезисы докладов. Вильнюс, $1977,28$.

Микалаускас В. В. Охрана подземных вод Литовской ССР. Вильнюс, 1976.

Микалаускас B. B. Организационные аспекты исследований загрязнения подземных вод Литовской ССР. - В кн.: Методы исследования загрязнения подземных вод Прибалтики. Тезисы докладов. Вильнюс, 1981, 17-18.

Пилль A. A. Подземные воды западного побережья и островов Эстонии и особенности их формирования. Автореф. канд. дис. Таллин, 1974.

Kink, H. Maaparandus ja põhjavee kaitse. - Rmt.: Põhjavee kasutamisest ja kaitsest Eesti NSV-s. Tln., 1978, 72-77.

Maastik, A. Pöllumajandus ja veekaitse. - Rmt.: Põhjavee kasutamisest ja kaitsest Eesti NSV-s. Tln., 1978, 77-89.

Ground Water Contamination in the Northeast States. Report of the Office of Research and Development U. S. Environmental Protection Agency. Washington, 1974.

\author{
Ннститут геологии \\ Академии наук Эстонской ССР
}

\title{
Поступила в редакцию
} 22/XI 1984

\section{P. JOGAR}

\section{MONEDE ANTROPOGEENSETE NING LOODUSLIKE TEGURITE MOJU POHJA-EESTI POHJAVETE KEEMILISELE KOOSTISELE}

Karbonaatsete kivimite maapinnalähedastes kihtides tsirkuleeriv põhjavesi allub PōhjaEestis suurel määral põllumajandusliku tegevuse mõjule. Ilmneb pốhjavee üldmineralisatsiooni (ioonide summa) -suurenemise tendents. Mineralisatsioon ei suurene Kesk-Eesti vōimsate tektooniliste rikkevööndite levikualal ning Vooremaal, kus pinnakate on suhteliselt paks.

Artiklis on lähemalt vaadeldud põhjavete hüdrokeemilist tsonaalsust ning tektooniliste rikkevööndite mõju mineralisatsioonile, et elimineerida nende looduslike tegurite osatähtsus üldmineralisatsiooni suurenemisel. Kasutatud on ligi 800 ekspluatatsioonilise puuraugu andmeid aastaist 1958-1973.

\section{P. JOGAR}

\section{RESEARCH INTO THE EFFECT OF AGRICULTURAL ACTIVITIES UPON THE CHEMICAL COMPOSITION OF GROUND WATER (IN NORTH ESTONIA)}

The effect of agricultural activities upon the composition of ground water was studied in North Estonia (Figure), an area of distribution of carbonaceous rocks overlain mainly by a thin $(1-5 \mathrm{~m})$ layer of Quaternary deposits. For eliminating the effect of natural factors in the study of that process, a preliminary investigation of the vertical hydrochemical zoning of ground water was carried out at a depth of $100 \mathrm{~m}$ from the surface of the earth (Table 1) as well as a study of the effect of the fracture areas and fault zones (Table 2). In agricultural areas the tendency of an increase in the mineralization of ground water (at a depth of up to $30 \mathrm{~m}$ ) was observed; this phenomenon did not occur only in greater fracture areas and in the presence of a thick layer surface cover (the Vooremaa drumlin area; Table 3). Data were obtained (1958-1973) from analyses of all water wells situated beyond the borders of rural settlements. In the future it is planned to carry out observations of the discussed process by ten-year periods. 